\title{
Soroprevalência da arterite viral equina em mesorregiões paulistas entre 2007 e 2008
}

\section{Seroprevalence of equine viral arteritis in paulista mesoregions between 2007 and 2008}

\author{
Pollyana Rennó Campos Braga ${ }^{1}$; Maria do Carmo Custódio de Souza Hunold \\ Lara $^{2}$; Adriano Dias ${ }^{3}$; Elenice Maria Sequetin Cunha ${ }^{4}$; Eliana Monteforte Cassaro \\ Villalobos ${ }^{4}$; Márcio Garcia Ribeiro ${ }^{3}$; Alexandre Secorun Borges ${ }^{3 *}$
}

\section{Resumo}

\begin{abstract}
O presente estudo investigou a ocorrência de anticorpos contra o vírus da arterite equina, utilizando a técnica de soroneutralização em 1.400 equinos criados nas mesorregiões macro metropolitana paulista e Campinas do estado de São Paulo (SP), entre os anos de 2007 e 2008. Do total das amostras, 80 (5,7\%) apresentaram anticorpos para o vírus (títulos entre 4 e 4096). Dentre os 42 municípios amostrados, $15(35,7 \%)$ apresentaram pelo menos um animal sororeagente. Foram analisadas 238 propriedades das quais 41 apresentaram ao menos um animal sororeagente. A ocorrência de animais reagentes foi maior em cavalos que eram utilizados para práticas esportivas, particularmente das raças utilizadas para salto e Quarto de Milha e foi semelhante entre machos e fêmeas. A soropositividade também foi maior em animais com idade superior a 24 meses. Os resultados obtidos sugerem a circulação do vírus da arterite equina nos criatórios amostrados e reforçam a necessidade de estudos continuados de vigilância epidemiológica.
\end{abstract}

Palavras-chave: Vírus da arterite equina, anticorpos, cavalo, Brasil

\begin{abstract}
This study investigated the occurrence of equine arteritis virus antibodies using neutralization test in 1,400 horses from Campinas and macro metropolitan paulista mesoregions located at Sao Paulo State, between 2007 and 2008. Eighty (5.7\%) samples showed antibodies to virus (titers from 4 to 4,096). Among the 42 cities, 15 (35.7\%) presented at least one seropositive animal to equine arteritis virus. Of the 238 farms analyzed 41 showed at least one seropositive animal. The occurrence was higher in sport horses like jumping horses, Quarter horses and was similar for female and male. The rate of seropositive was higher in animals older than 24 months of age. These results suggest the virus circulation among horse population in studied farms, and the need for continuing epidemiological surveillance studies.

Key words: Equine arteritis virus, antibodies, horse, Brazil
\end{abstract}

1 Médica Veterinária, Universidade Estadual Paulista, UNESP, FMVZ, Botucatu, SP. E-mail: pollyrcb@yahoo.com.br

2 Pesquisadora do Instituto Biológico, São Paulo, SP. E-mail: lara@biologico.sp.gov.br

3 Profs. da Universidade Estadual Paulista, UNESP, FMB, Botucatu, SP. E-mail: adias@fmb.unesp.br; mgribeiro@fmvz.unesp.br; asborges@fmvz.unesp.br

4 Pesquisadores do Instituto Biológico, São Paulo, SP. E-mail: cunha@biologico.sp.gov.br; villalobos@biologico.sp.gov.br

* Autor para correspondência 


\section{Introdução}

A arterite viral equina é reconhecida como doença infecto-contagiosa, causada por vírus da família Arteriovirídae, denominado vírus da arterite equina (equine arteritis virus - EAV), caracterizada por lesões no endotélio dos vasos sanguíneos. A doença se manifesta sob a forma de abortamentos e sinais respiratórios (pneumonia intersticial). Os prejuízos decorrentes da infecção pelo vírus nos plantéis são representados pela ocorrência de abortamentos, morte de potros, redução no desempenho atlético dos animais, na eficiência reprodutiva dos machos e por sanções internacionais no uso do sêmen e trânsito de animais soropositivos ou de regiões endêmicas (LIMA; OSÓRIO, 2007). Os machos infectados podem permanecer portadores do vírus e são considerados responsáveis pela manutenção da infecção nos criatórios (BALASURIYA; MAcLACHLAN, 2007).

A soroprevalência da infecção pelo EAV foi estimada em 11,3\% na Suíça, 18,5\% na França, $2,3 \%$ na Inglaterra, $20 \%$ na Alemanha e $27 \%$ na Polônia (HOLYOAK et al., 2008). Recentemente, oito surtos de arterite viral equina foram descritos na Argentina envolvendo 196 equinos (OIE, 2010).

No Brasil foi descrita soroprevalência de 18,2\% no estado de São Paulo (LARA et al., 2002), 2,9\% na cidade de Curitiba (LARA et al., 2003), 2,2\% no estado do Rio Grande do Sul (DIEL et al., 2006) e $0,85 \%$ no estado de Minas Gerais (BELLO et al., 2007). Em contraste, Heinemann et al. (2002) no município de Uruará no Pará, Lara et al. (2006) em cavalos de carroceiros da cidade e região Metropolitana de Curitiba, Aguiar et al. (2008) no município de Monte Negro, Rondônia, e Cunha et al. (2009) em 16 municípios do sul do estado de São Paulo, não identificaram animais soropositivos para o EAV. Até o momento nenhum surto da doença foi identificado no país.

A prevalência da infecção pode ser influenciada por fatores como idade, raça e forma de utilização dos animais (BALASURIYA; MAcLACHLAN,
2007). Os títulos de anticorpos são maiores em fêmeas e em cavalos utilizados para reprodução e, as maiores taxas de infecção em animais mais velhos indicam que os cavalos, com o passar dos anos, podem ser repetidamente expostos ao vírus (BALASURIYA; MAcLACHLAN, 2007).

Considerando a relevância da equideocultura no estado de São Paulo, a presença de diferentes criatórios de elite no estado e o reduzido número de estudos sobre a doença, o presente estudo investigou a ocorrência de anticorpos para o EAV em equinos das mesorregiões macro metropolitana paulista e de Campinas.

\section{Material e Métodos}

O cálculo amostral foi baseado nos dados do IBGE (Instituto Brasileiro de Geografia e Estatística) do ano de 2005, no qual o estado de São Paulo é subdividido em 15 mesorregiões geográficas contendo 63 microrregiões. Foram colhidas amostras de soros sanguíneos de equinos criados em cinco microrregiões geográficas (Bragança Paulista, Jundiaí, Amparo, Campinas e Mogi Mirim), pertencentes às mesorregiões de Campinas e macro metropolitana paulista, incluindo 238 propriedades em 42 municípios.

O número de amostras foi calculado frente a uma população estimada de 47.356 equinos. A prevalência da doença foi estimada em $6 \%( \pm 2 \%)$, considerando como dois o efeito de delineamento pelas dificuldades na amostragem sistemática, resultando na avaliação de, no mínimo, 1.069 animais, com o intuito de obter intervalo de confiança de 95\%. A título de confiabilidade dos resultados foram avaliados no presente estudo 1.400 animais. Foram colhidas 665 (47,5\%) amostras de soro de animais pertencentes ao sexo masculino e $735(52,5 \%)$ amostras pertencentes a animais do sexo feminino. Os equinos foram subdivididos em cinco grupos: animais com idade igual ou inferior a 6 meses de idade (33 animais), animais acima de 6 meses e igual ou inferior a 24 meses de idade 
(239 animais), animais acima de 24 meses e igual ou inferior a 72 meses de idade (483 animais), animais acima de 72 meses e igual ou inferior a 120 meses de idade (365 animais) e animais com idade superior a 120 meses de idade (280 animais). O teste de quiquadrado foi utilizado para verificar se o grupo etário influenciou a soropositividade.

As amostras de sangue foram colhidas de equinos sem histórico anterior de vacinação contra o EAV, no período compreendido entre janeiro de 2007 e dezembro de 2008. As amostras foram processadas no Laboratório de Raiva e Encefalites do Instituto Biológico de São Paulo.

Para a pesquisa de anticorpos contra o EAV foi utilizada a técnica de soroneutralização em microplacas. Os soros foram avaliados em diluições na base 2 frente a 100 TCID $_{50} / 25 \mu \mathrm{L}$ de suspensão do EAV (amostra Bucyrus). Após a incubação por 1 h, a $37{ }^{\circ} \mathrm{C}$ foram adicionados $100 \mu \mathrm{L}$ de suspensão de células RK-13, contendo 300.000 células $/ \mathrm{mL}$. A leitura foi realizada após $72 \mathrm{~h}$ de incubação em estufa com $5 \%$ de $\mathrm{CO}_{2}$, a $37{ }^{\circ} \mathrm{C}$, observando a neutralização do efeito citopático (LARA et al., 2002; 2003). Foram considerados reagentes os soros com título $\geq 4$, conforme recomendação da Organização Mundial de Saúde Animal.

\section{Resultados e Discussão}

Das 1.400 amostras de soro sanguíneo analisadas pela técnica de soroneutralização, 80 (5,71\%) apresentaram anticorpos contra o EAV.

Dentre os 42 municípios amostrados, 15 (35,7\%) apresentaram ao menos um animal soropositivo para a arterite viral equina sendo cinco municípios pertencentes à mesorregião geográfica de Campinas (Jaguariúna, Santo Antônio da Posse, Socorro, Valinhos, Campinas e Sumaré) e 10 municípios pertencentes à mesorregião geográfica macro metropolitana paulista (Bragança Paulista, Bom Jesus dos Perdões, Joanópolis, Piracaia, Atibaia, Jundiaí, Morungaba, Vargem e Nazaré Paulista).
As cinco cidades que apresentaram maior ocorrência de animais soropositivos foram: Sumaré (28,6\%), Nazaré Paulista (25\%), Vargem (14,3\%), Campinas (13,8\%) e Morungaba (13,3\%). Das 238 propriedades estudadas, 41 possuíram ao menos um animal soropositivo, das quais Campinas (18 propriedades) e Bragança Paulista (5 propriedades) foram os municípios com maior número de animais reagentes.

Das 80 amostras soropositivas para o EAV, 6\% (40/665) foram de animais do sexo masculino e $5,4 \%(40 / 735)$ do sexo feminino. Esta ocorrência similar não caracterizou influência do sexo dos animais na ocorrência da infecção diferentemente de Balasuriya e Maclachlan (2007) que apontaram maior prevalência da infecção em fêmeas.

Foi constatada a seguinte frequência de anticorpos para o EAV nos equinos deste estudo: animais utilizados para salto (17,9\%), Quarto de Milha (10\%), Crioulo (6,7\%), Árabe (6,7\%), semraça-definida (6,1\%), Lusitano (3,5\%), Mangalarga $(3,4 \%)$, Campolina $(2,2 \%)$, Puro Sangue Inglês $(1,3 \%)$. Nos animais amostrados foi observada maior soropositividade em animais utilizados para esportes equestres. Este achado concorda com estudos similares conduzidos em outros países que também demonstram maior predisposição à infecção nessa categoria (BALASURIYA; MAcLACHLAN, 2007). No entanto, destoam de investigações prévias realizadas no Brasil que apontaram maior prevalência de animais soropositivos da raça Mangalarga (33,3\%) no estado de São Paulo (LARA et al., 2002).

As taxas de animais soropositivos para o EAV variaram de acordo com a faixa etária sendo encontrados $2,5 \%$ de soropositividade na faixa de 0 a 6 meses; $3 \%$ de 6 a 24 meses; 6,4\% de 24 a 72 meses; $6,5 \%$ de 72 a 120 meses e de $6,4 \%$ nos equinos com idade superior a 120 meses. A maior ocorrência de animais soropositivos para o EAV em equinos com idade superior a 24 meses $(p=0,012)$ esta de acordo com estudo similar que refere o 
aumento da soroprevalência com o avançar da idade, indicando maior risco de exposição ao vírus em animais adultos, em plena atividade reprodutiva, ou ligada ao uso em esportes equestres, treinamentos ou tração (BALASURIYA; MACLACHLAN, 2007).

A taxa de animais soropositivos foi menor que a encontrada por Lara et al. (2002), que evidenciaram $18,2 \%$ de cavalos soropositivos no estado de São Paulo. No entanto, a soroprevalência encontrada no presente estudo foi superior a todos os outros estudos similares conduzidos em equinos no Brasil (HEINEMANN et al., 2002; LARA et al., 2003; DIEL et al., 2006; LARA et al., 2006; BELLO et al., 2007; AGUIAR et al., 2008; CUNHA et al., 2009). Os estudos demonstraram que os estados brasileiros que possuem maior aglomeração de animais e intensa atividade equestre, apresentaram maior frequência de anticorpos para o EAV (LARA et al., 2002, LARA et al., 2003; DIEL et al., 2006). A ocorrência de maiores taxas de animais soropositivos poderia ser creditada ao favorecimento da transmissão do vírus em regiões ou estados que possuem alta atividade equestre e de reprodução. A influência das condições de criação dos animais na ocorrência da infecção também foram evidenciadas em dois estudos conduzidos em Curitiba e região metropolitana nos quais Lara et al. (2003) verificaram 2,9\% de animais positivos em animais da raça Puro Sangue Inglês e ausência de sororeagentes em animais utilizados para tração de carroças (LARA et al., 2006).

\section{Conclusão}

Surtos recentes de arterite viral equina ocorridos em cavalos de esporte na Argentina (OIE, 2010) reafirmam a preocupação com a doença, a presença do vírus na América do Sul e o risco de transmissão do vírus para a população de equinos do Brasil, uma vez que é intenso o trânsito de animais entre os estados do sul e sudeste do país e a Argentina. Medidas zoosanitárias específicas para a arterite viral equina foram adotadas pelo Ministério da
Agricultura, Pecuária e Abastecimento no ano de 2008 (MAPA, 2008). No entanto, os requisitos exigidos para a importação temporária de equinos com retorno à origem, ainda oferecem risco para a introdução do vírus em nosso país.

Os resultados do presente estudo evidenciam a circulação do EAV nos criatórios nas mesorregiões paulistas estudadas e reforçam a necessidade de estudos continuados de vigilância epidemiológica com o intuito de avaliar a ocorrência da doença e reduzir o risco sanitário e o impacto econômico negativo da arterite viral para a equideocultura nacional.

\section{Comissão de Ética e Experimentação Animal}

Os procedimentos realizados foram previamente aprovados pela Comissão de Ética no Uso de Animais da Faculdade de Medicina Veterinária e Zootecnia, Campus de Botucatu - Universidade Estadual Paulista ( ${ }^{\circ}$ CEUA - 110/2008).

\section{Referências}

AGUIAR, D. M.; CAVALCANTE, G. T.; VILLALOBOS, E. M. C.; CUNHA, E. M. S.; OKUDA, L. H.; DE STÉFANO, E.; SOUZA, G. O.; VASCONCELLOS, S. A.; LABRUNA, M. B.; CAMARGO, L. M. A.; GENNARI, S. M. Prevalência de anticorpos contra agentes virais e bacterianos em eqüídeos do município de Monte Negro, Rondônia, Amazônia Ocidental Brasileira. Brazilian Journal of Veterinary Research and Animal Science, São Paulo, v. 45, n. 4, p. 269-276, 2008.

BALASURIYA, U. B. R.; MACLACHLAN, N. J. Equine viral arteritis. In: SELLON, C. D.; LONG, T. M. Equine infectious diseases. St. Louis, Missouri: Saunders Elsevier, cap. 14, p. 153-164.

BELLO, A. C. P. P.; CUNHA, A. P.; BRAZ, G. F.; LARA, M. C. S. H.; REIS, J. K. P.; HADDAD, J. P. H.; ROCHA, M. A.; LEITE, R. C. Frequency of equine viral arteritis in Minas Gerais State, Brazil. Arquivo Brasileiro de Medicina Veterinária e Zootecnia, Belo Horizonte, v. 59, n. 4, p. 1077-1079, 2007.

CUNHA, E. M. S.; VILLALOBOS, E. M. C.; NASSAR, A. F. C.; LARA, M. C. C. S. H.; PERES, N. F.; PALAZZO, J. P. C.; SILVA, A.; STEFANO, E. de; PINO, 
F. A. Prevalência de anticorpos contra agentes virais em eqüídeos no sul do Estado de São Paulo. Arquivos do Instituto Biológico, São Paulo, v. 76, n. 2, p. 165-171, 2009. Disponível em: <http://www.biologico.sp.gov.br/ docs/arq/v76_2/cunha2.pdf.>. Acesso em: 22 set. 2011.

DIEL, D. G.; ALMEIDA, S. R.; WEIBLEN, R.; FRANDALOSO, R.; ANZILIERO, D.; KREUTZ, L. C.; GROFF, F. H. S.; FLORES, E. F. Prevalência de anticorpos contra o vírus da Influenza, da arterite viral e herpesvírus em equinos do Estado do Rio Grande do Sul, Brasil. Ciência Rural, Santa Maria, v. 36, n. 5, p. 1467-1673, 2006.

HEINEMANN, M. B.; CORTEZ, A.; SOUZA, M. C. C.; GOTTI, T.; FERREIRA, F.; HOMEM, V. S. F.; FERREIRANETO, J. S.; SOARES, R. M.; SAKAMOTO, S. M.; CUNHA, E. M. S.; RICHTZENHAIN, L. F. Soroprevalência da anemia infecciosa equina, da arterite viral dos equinos e do aborto viral eqüino no município de Uruará, PA, Brasil. Brazilian Journal of Veterinary Research and Animal Science, São Paulo, v. 39, n. 1, p. 50-53, 2002.

HOLYOAK, G. R.; BALASURIYA, U. B. R.; BROADDUS, C. C.; TIMONEY, P. J. Equine viral arteritis: Current status and prevention. Theriogenology, Philadelphia, v. 70, n. 3, p. 403-414, 2008.

LARA, M. C. C. S. H.; CASTRO, A. F.; BIRGEL, E. H.; FERNANDES, W. R. Pesquisa de anticorpos contra o vírus da arterite dos equinos (VAV) e herpes equino tipo 1, em cavalos criados em Curitiba, PR. A Hora Veterinária, Porto Alegre, v. 23, n. 135, p. 51-53, 2003.
LARA, M. C. C. S. H.; FERNANDES, W. R.; TIMONEY, P. J.; BIRGEL, E. H. Prevalência de anticorpos antivírus da arterite dos equinos em cavalos criados no Estado de São Paulo. Arquivo Brasileiro de Medicina Veterinária e Zootecnia, Belo Horizonte, v. 54, n. 3, p. 223-227, 2002.

LARA, M. C. C. S. H.; FURMAN, K. E.; BARROS FILHO, I. R.; VILlALOBOS, E. M. C.; CUNHA, E. M. S.; DECONTO, I.; BONACIM, J.; BIONDO, A. W. Detection of antibodies against equine viral arteritis (EVAV) and equine herpesvirus type 1 (EHV-1) in cart horses from Curitiba and surroundings, southern Brazil. Archives of Veterinary Science, Curitiba, v. 11, n. 3, p. 11-14, 2006.

LIMA, M.; OSÓRIO, F. A. Arterivirídae. In: FLORES, E. F. Virologia veterinária. Santa Maria, RS: UFSM, p. 646-649, 2007.

MAPA. Programa nacional de sanidade dos equinos (PNSE). Trânsito, 28 março. 2008. Disponível em: $<\mathrm{http}: / / w w w . a g r i c u l t u r a . g o v . b r .>$. Acesso em: 17 maio 2011.

OIE. Equine viral arteritis, Argentina. World animal health information database. 2010. Disponível em: $<$ http://www.oie.int/wahis/public.php?page=weekly_ report_index\&admin=0.>. Acesso em: 16 ago. 2011. 
